\title{
Enhancement of drought tolerance in Triticum aestivum L. seedlings using Azospirillum brasilense NO40 and Stenotrophomonas maltophilia B1 1
}

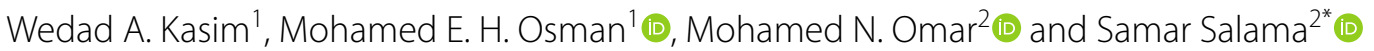

\begin{abstract}
Background: The effectiveness of two PGPB; Azospirillum brasilense NO40 and Stenotrophomonas maltophilia B1 1 was investigated in enhancing the drought tolerance of wheat (Triticum aestivum L.) seedlings cultivar Gemiza9. The inoculated or uninoculated grains were sown in unsterilized sandy soil and watered normally untill the $8^{\text {th }}$ day. Drought stress was initiated by completely withholding water for 7 days (until wilting). Samples were collected after 15 days from sowing to evaluate some growth criteria, damage and defense indicators and to analyze the roots' protein pattern.

Results: The results showed that inoculating wheat seedlings with these strains significantly diminished the inhibitory effects of drought stress on the relative water content of roots, shoots and leaves; area of leaves; contents of pigments (chlorophyll a and b) and ascorbic acid; and on the protein patterns of roots. Moreover, the bacterial inoculation notably reduced the drought-induced damage indicated by lower leakage of electrolytes and less accumulation of Malondialdehyde and hydrogen peroxide, surprisingly with less enhanced production of proline and activities of catalase and peroxidase than their uninoculated counterparts. Under normal conditions, inoculating wheat plants with these PGPB resulted in significantly promoted growth and elevated contents of pigments and altered protein patterns of roots.
\end{abstract}

Conclusion: Overall, we can say that both Azospirillum brasilense NO40 and Stenotrophomonas maltophilia B11 were able to deactivate the growth inhibition in wheat seedlings to some extent, while maintaining a certain level of efficient protection against damage under drought stress.

Keywords: Drought, Growth, Plant growth promoting bacteria, Tolerance, Wheat

\section{Background}

Water is the main limiting factor for plant growth, development, and productivity; as the plant requires within reach of its roots, water of adequate quality, in appropriate quantity and at the right time (FAO 2003). Consequently, the lack of adequate moisture, i.e. drought stress,

\footnotetext{
*Correspondence: samarsalama7@yahoo.com

${ }^{2}$ Microbiology Department, Soils, Water and Environment Research

Instiute, Agriculture Research Centre, Giza, Egypt

Full list of author information is available at the end of the article
}

permanent or temporary, can trigger a wide range of highly complicated morphological, anatomical, biochemical and molecular plant responses (Farooq et al. 2009; Takahashi et al. 2020).

Some plant responses are deleterious: lost turgor, arrested growth, disturbed water relations, diminished water-use efficiency, reduced transpiration and photosynthesis, injured cell membranes and macromolecules, altered activities of various enzymes, modified metabolism and assimilate partitioning, enhanced reactive oxygen species (ROS) production, declined yields, and 
may be accelerated senescence and death (Farooq et al. 2009; Bodner et al. 2015). Other plant responses can be adaptive: the plant may:- enhance the water uptake by maintaining root growth; reduce water loss by closing stomata, restricting shoot growth, accelerating leaf senescence..., etc.; accumulate protective molecules; activate its antioxidative defense; stabilize its membranes; regulate hormones, proteins and expression of genes; and/ or it may speed its development or even complete its life cycle before the onset of drought stress (Farooq et al. 2009; Bodner et al. 2015; Takahashi et al. 2020).

It is worth noting that the same response can be seen as adaptive or deleterious, depending on how far it helps the plant to balance between maintaining growth and reproduction on one hand, and ensuring survival on the other hand (Claeys and Inze 2013). For instance, growth arrest is a primary response of plants subjected to drought stress (Bhargava and Sawant 2013), and this arrest is usually translated into important loss in amount and quality of crop yield (Farooq et al. 2009; Bodner et al. 2015). But if the stress is only temporary, limiting growth too extensively can lead to unnecessary yield losses; on the other hand, continued growth can threaten survival when water limitation turns out to be long and severe (Claeys and Inze 2013). Therefore, it is crucial for plants to balance between growth and survival in order to maintain the best yields as they can (Claeys and Inze 2013). However, achieving this balance is highly complex and variable depending on the plant species, genotype, age, developmental stage, organ, cell type and cellular compartment, in addition to the duration, severity and rate of progression of water loss and interaction with other environmental conditions (Ngara and Ndimba 2014).

Different strategies have been adopted to enhance the crops' performance under the restricted water availability (Mancosu et al. 2015). Among these strategies, is the use of the free-living plant growth promoting bacteria (PGPB) as a relatively simple, handy, low-cost, and ecofriendly strategy (Figueiredo et al. 2016; Goswami and Deka 2020). They are characterized by their ability to colonize roots excellently, and to produce various enzymes and metabolites, by which they can induce physical and chemical changes in plants, resulting in enhanced tolerance to abiotic stresses (Ngumbi and Kloepper 2016). These induced changes have been termed by Yang et al. (2009) as the induced systemic tolerance. As a result, many PGPB have been used to promote the survival, growth, and productivity of several crops under drought stress such as; maize (Fan et al. 2015; Jochum et al. 2019) and wheat (Kasim et al. 2013; Timmusk et al. 2014; Jochum et al. 2019).

This study was the fourth, exploring how far two selected PGPB: Azospirillum brasilense NO40 and
Stenotrophomonas maltophilia B11 can be a promising tool for enhancing the drought tolerance of wheat cultivar Gemiza9 (Omar et al. 2017; Salama 2019; Osman et al. 2020). The previous studies indicated that both strains: (1) possess multiple plant growth promoting traits ( $\mathrm{N}_{2}$ fixation, 1-Amino-Cyclopropane-1-Carboxylate (ACC) -deaminase activity, P-solubilization and production of $\mathrm{HCN}$, ammonia, and phytohormones (Indole Acetic Acid (IAA), Gibberellic Acid (GA) and Abscisic Acid (ABA)); (2) can tolerate osmotic stress up to -26.82 bar (50\% polyethylene glycol 6000); (3) enhanced the wheat seedlings' growth in vitro (in a sterilized system (spermosphere model)) under normal and osmoticstressed (25\% PEG6000 =-7.35 bar); (4) gave the wheat seedlings superior growth, survival and recovery in vivo than the uninoculated seedlings where the plants were exposed to a period of drought stress (17 days of ceasing irrigation) followed by a period of recovery (10 days of reirrigation) and (5) significantly reduced the droughtinduced loss in wheat yield where the inoculated plants maintained significantly higher values of all of the measured yield parameters, and the yielded grains had higher amounts of the direct reducing sugars, sucrose, starch; lower contents of total soluble proteins; and the total free amino acids, and altered protein patterns compared to those of the uninoculated-drought-stressed plants.

The aims of the current study are to investigate the reproducibility of the positive impact of these PGPB (Azospirillum brasilense NO40 and Stenotrophomonas maltophilia B11) on wheat growth under normal and drought-stressed conditions and to explore how far these strains can help wheat seedlings to maintain optimal growth under drought stress conditions without sacrificing survival, through evaluating some damage and defense indicators.

\section{Methods \\ Plant material}

Grains of wheat (Triticum aestivum L.) cultivar Gemiza9 (cv. G9) were obtained from the Wheat Department, Field Crops Research Institute, Agriculture Research Centre (ARC), Giza, Egypt, where cv.G9 is a relatively drought-sensitive, but high-yielding, rust-resistant, and wide-cultivating cultivar in Egypt (El-Shami et al. 2000).

\section{Microorganisms}

The used PGPB were Azospirillum brasilense NO40 and Stenotrophomonas maltophilia B11 isolated from rice (Omar et al. 1989) and wheat rhizosphere (Salama 2019), respectively. Both strains were allowed to grow in nutrient broth for $24 \mathrm{~h}$ at $28{ }^{\circ} \mathrm{C}$ with shaking, after which the culture turbidity was adjusted to $0.3 \sim 10^{8}$ colony-forming unit $(\mathrm{CFU}) / \mathrm{ml}$ (using the spectrophotometer at $600 \mathrm{~nm}$ ) to be 
used either for grain coating or liquid inoculation. For the grain coating, $30 \mathrm{ml}$ of each culture was taken to inoculate bags of vermiculite carrier $(50 \mathrm{~g} / \mathrm{bag})$ and incubated for $24 \mathrm{~h}$, while for liquid inoculation the fresh cultures were mixed with irrigation water $(5 \mathrm{ml} / \mathrm{pot})$ twice, after sowing and on the $8^{\text {th }}$ day from sowing.

\section{Plant growth and treatments}

The experiment was conducted at the Experimental Green house of Wheat Department, Field Crops Research Inst., (ARC), Giza, Egypt, using soil with sandy texture obtained from the Agricultural Research Station, Ismailia, ARC, Giza, Egypt. Its characteristics and composition are illustrated in Table 1.

The wheat grains were selected for apparent uniformity of shape and size, surface- sterilized by $\mathrm{HgCl}_{2} 0.1 \%$ for $5 \mathrm{~min}$. and rinsed 5 times with sterile tap water. Then, the grains were mixed with the inoculated carrier bags and Arabian gum solution on clean plastic sheets and left to be air-dried for $1 \mathrm{~h}$ in shadow before sowing. For the uninoculated treatments, a clean nutrient broth was added instead.

The experiment included 6 treatments, each treatment has 30 replica as follows: (1) Cont. (control) $=$ unstresseduninoculated treatment; (2) $\mathrm{B}_{1}=$ unstressed- inoculated with $A$. brasilense NO40, (3) $\mathrm{B}_{2}=$ unstressed-inoculated with S. maltophilia B11, (4) D=drought-stressed-uninoculated, (5) $\mathrm{DB}_{1}=$ drought-stressed-inoculated with A. brasilense $\mathrm{NO} 40$ and (6) $\mathrm{DB}_{2}=$ drought-stressed- inoculated with S. maltophilia B11.

Three inoculated or uninoculated grains were sown per pot $(9 \mathrm{~cm}$ height $\times 8.5 \mathrm{~cm}$ diameter containing $360 \mathrm{~g}$ of sandy soil) and left to grow at $20 \pm 2{ }^{\circ} \mathrm{C}$ in a relative humidity of $65 \%$ and $16 \mathrm{~h}$ photoperiod at $450 \mu \mathrm{mol} \mathrm{m}^{-2} \mathrm{~s}^{-1}$ light intensity and watered with $70 \%$ of the soil field capacity a day after day till the 8th day. Up to this point, the drought stress was initiated by completely withholding water for 7 days (until wilting). The unstressed pots were irrigated normally. The mineral fertilizer (N, P and $\mathrm{K}$ ) was applied according to the recommendations of the Egyptian Ministry of Agriculture.

Samples were collected after 15 days from sowing, some seedlings were taken immediately to measure the growth criteria, electrolytes leakage and $\mathrm{H}_{2} \mathrm{O}_{2}$ content, and some others were kept frozen at $-80^{\circ} \mathrm{C}$, while the rest were ovendried at $50^{\circ} \mathrm{C}$ for further analysis.

\section{Relative water content and leaf area}

The 15-day-old wheat seedlings were collected, washed immediately, dried between two filter papers and divided into roots and shoots. Fresh, fully turgid and dry masses of roots, shoots and the second node leaves were measured and used in the determination of the RWC according to Sharp et al. (1990). The leaf area was determined using the Leaf Area Measurement software (University of Sheffield A.P. Askew 2003).

\section{Photosynthetic pigments}

Photosynthetic pigments, chlorophyll a, chlorophyll b and carotenoids were determined quantitatively as described by Arnon (1949) for chlorophylls and Horváth et al. (1972) for carotenoids as adopted by Kissimon (1999).

\section{$\mathrm{H}_{2} \mathrm{O}_{2}$, malondialdehyd (MDA) and electrolyte leakage}

The content of $\mathrm{H}_{2} \mathrm{O}_{2}$ and the electrolyte leakage were measured in the immediately harvested fresh leaves using the method of Loreto and Velikova (2001) and Sairam et al. (1997), respectively, while the MDA content in leaves, as an indicator of drought-induced lipid peroxidation, was estimated according to Heath and Packer (1968).

\section{Ascorbic acid and free proline}

Ascorbic acid (A.A) content was estimated in leaves according to Oser (1979), while the free proline was determined according to the method described by Bates et al. (1973) in the root and shoot tissues.

\section{Assaying of catalase and peroxidase}

According to Beauchamp and Fridovich (1971), the extract of fresh plant martials was used for assaying catalase (EC 1.11.1.6) and peroxidase (EC 1.11.1.7) as described by Kato and Shimizu (1987).

\section{Qualitative characterization of protein of roots using SDS-PAGE}

The protein patterns of the root of 15-day-old wheat seedlings were analysed using one dimensional sodiumdodecyl sulphate poly acrylamide gel electrophoresis (SDSPAGE) as described by Laemmli (1970). The gel bands were scanned and analyzed by the gel documentation system that determines molecular mass (MM) in $\mathrm{kDa}$ of each polypeptide band in relation to a standard marker $(\mathrm{M})$ using

Table 1 Some chemical and physical characteristics of the soil

\begin{tabular}{|c|c|c|c|c|c|c|c|c|c|c|c|}
\hline \multirow[t]{2}{*}{ pH } & \multirow[t]{2}{*}{$\mathrm{EC}(\mathrm{dS} / \mathrm{m})$} & \multicolumn{3}{|c|}{ Structure \% } & \multicolumn{7}{|c|}{ Mineral composition (mg/ Kg soil) } \\
\hline & & Sand & Silt & Clay & $\mathbf{N}$ & $\mathbf{P}$ & $\mathbf{K}$ & $\mathrm{Fe}$ & Mn & $\mathrm{Zn}$ & $\mathrm{Cu}$ \\
\hline 7.72 & 0.50 & 89.4 & 7.60 & 3.00 & 15.10 & 4.85 & 60.80 & 5.30 & 0.92 & 0.48 & 0.05 \\
\hline
\end{tabular}


the Gel Proanalyzer version 3 Media Cybernetics Imaging Exports software (Gel Doc. 2001 BioRad System).

\section{Statistical analysis}

All analytical determinations were replicated at least three times and the presented data are the mean values. The obtained results were subjected to one way analysis of variance ANOVA to determine the significance between treatments using CoStat software $(6,3)$ (CoHort software, California, USA 1998).

\section{Results}

\section{Relative water content and leaf area}

Generally, both of A. brasilense NO40 and S. maltophilia B11 revealed an evident promoting effect on the growth of wheat seedlings under all conditions and induced better tolerance to drought stress, which was clear from the healthier seedlings and the less severe wilting symptoms with respect to the uninoculated seedlings as revealed in Fig. 1.

Ceasing irrigation for 7 days dramatically reduced the relative water contents (RWC \%) of roots and shoots of both uninoculated and inoculated wheat seedlings (Fig. 2a, b). Without PGPB, RWC\% was dropped to 34\% in roots and $38 \%$ in shoots. The inoculation with $\mathrm{A}$. brasilense and S. maltophilia significantly improved the RWCs of roots to be $53 \%$ and $64 \%$, respectively and to $\geq 65 \%$ in shoots under drought stress. In leaf, drought stress resulted in remarkable reduction in its RWC (62\%) and area (24\%) in the uninoculated stressed leaf (Fig. 2c, d), while the corresponding reductions in the $\mathrm{B}_{1}$ or $\mathrm{B}_{2}$ - inoculated-drought-stressed seedlings were $\leq 13 \%$, and $52 \%$, respectively.
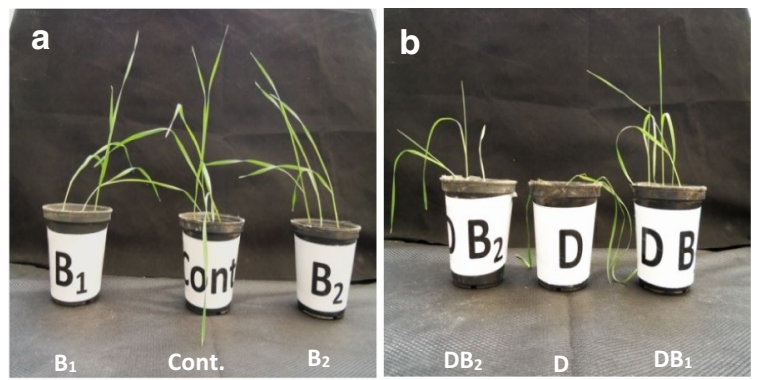

Fig. 1 Effect of bacterial inoculation with Azospirillum brasilense NO40 $\left(B_{1}\right)$ and Stenotrophomonas maltophilia B11 $\left(B_{2}\right)$ on the 15-day-old Triticum aestivum L. (cv. G9) seedlings grown in sandy soil, under unstressed (a) and drought-stressed (7 days of water withholding) (b) conditions. Cont. $=$ the unstressed-uninoculated control; $\mathrm{D}=$ the drought-stressed-uninoculated treatment, $\mathrm{B}_{(1-2)}=$ the unstressed-inoculated treatments and $\mathrm{DB}_{(1-2)}=$ the drought-stressed-inoculated treatments

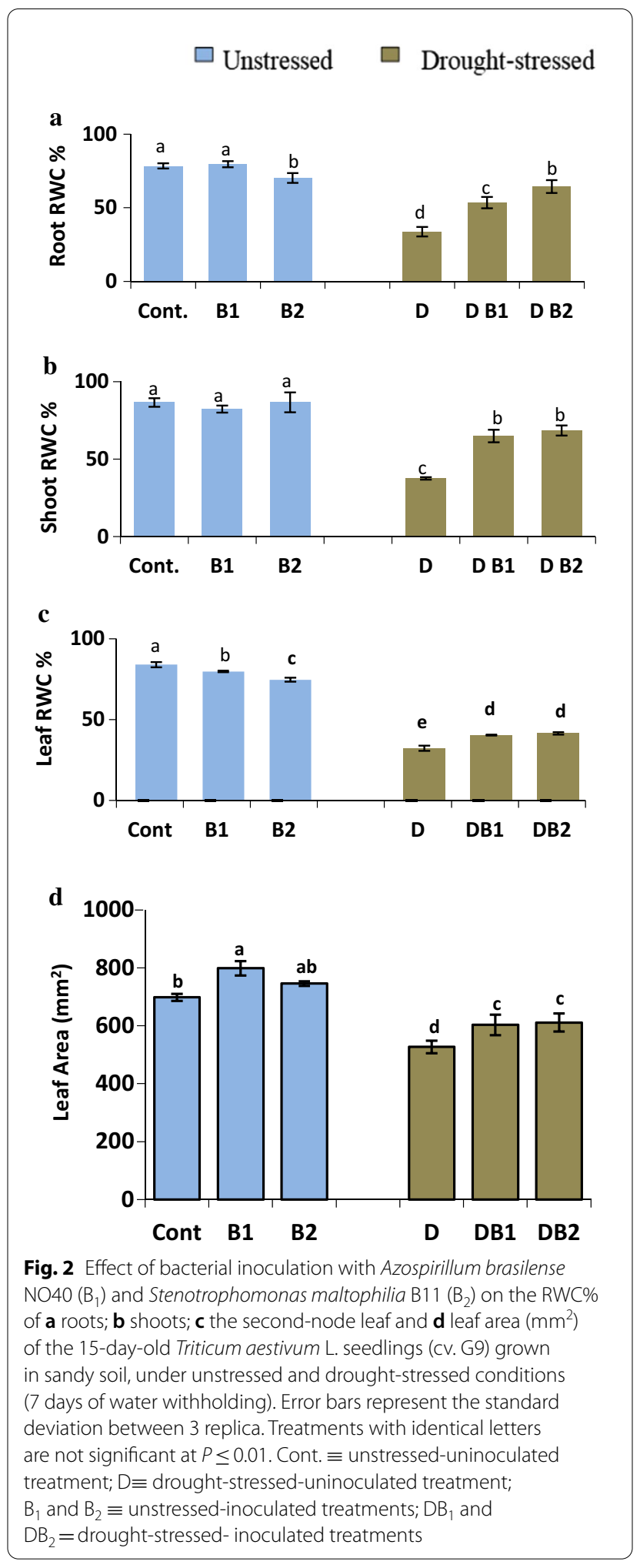

\section{Photosynthetic pigments}

The results indicate that the pigments contents were significantly reduced in response to 7 days of drought stress 
in all treatments (Fig. 3). The leaves of the uninoculatedt-stressed seedlings (D) had the least amount of chl-a and $-\mathrm{b}$ ( $38 \%$ and $41 \%$, respectively), less than those of the uninoculated-unstressed control, while the ratio of chl a/b was insignificantly affected, compared with the control. On contrary, the inoculation with $B_{1}$ and $B_{2}$ significantly reversed the negative effects of drought stress; where chl-a was 8.5 and $10.4 \mathrm{mg} / \mathrm{g} \mathrm{DM}$ in the $\mathrm{B}_{1}$ and $\mathrm{B}_{2}$-inoculated-stressed seedlings, respectively, compared

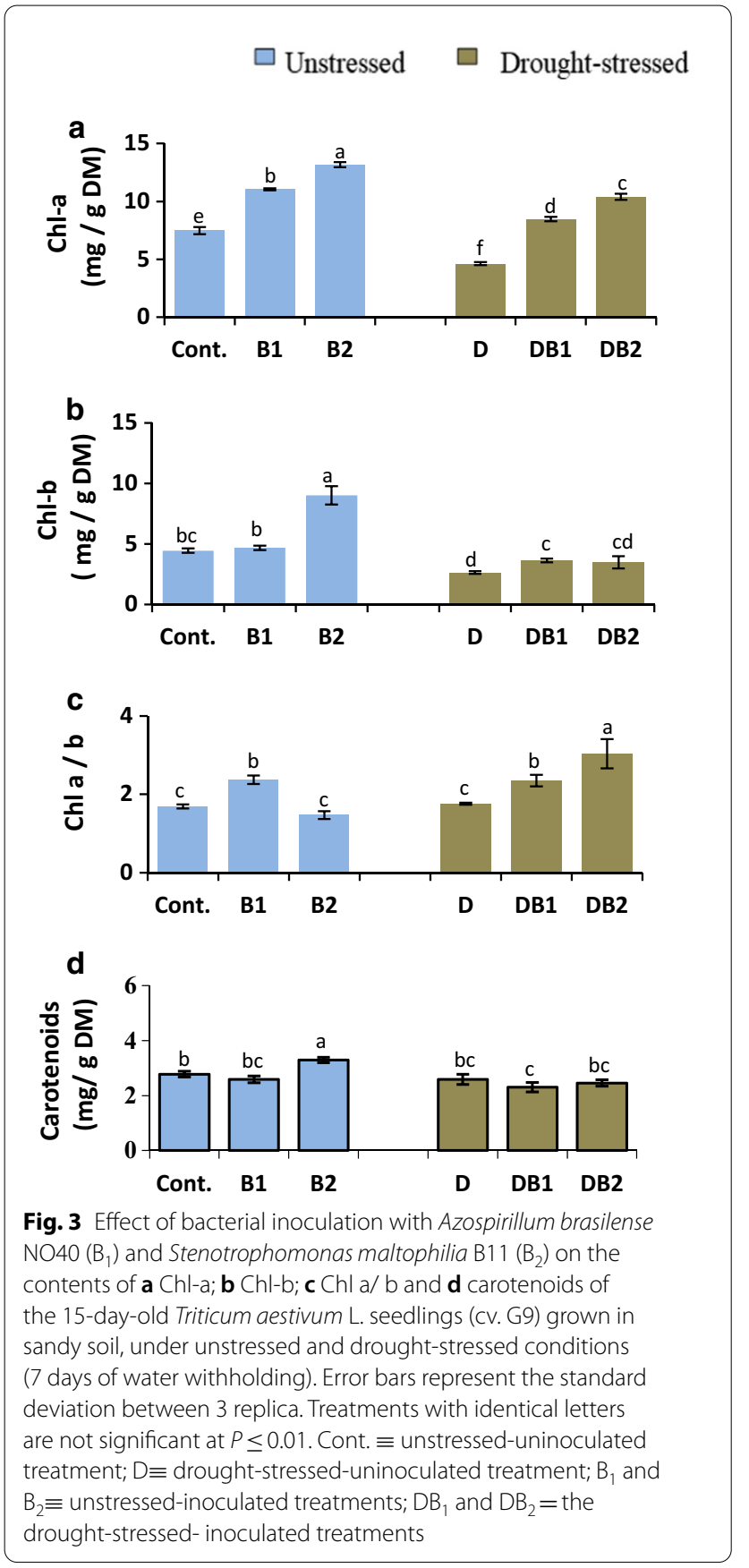

with $7.5 \mathrm{mg} / \mathrm{g}$ DM in the well-watered-uninoculated control. Similarly, in the $B_{1}$ and $B_{2}$-inoculated-stressed seedlings, chl-b increased by about $38 \%$ and $32 \%$, respectively than those of the uninoculated-stressed counterparts (D). Meanwhile, the two strains had different impacts on the chl a/b ratio under drought stress; where it was non-significantly affected in the $B_{1}$-inoculated-stressed seedlings $\left(\mathrm{DB}_{1}\right)$, compared with their $\mathrm{B}_{1}$-inoculated-unstressed counterparts, while the $B_{2}$-treated-stressed seedlings $\left(D_{2}\right)$ showed the highest chl a/b ratio among all treatments (3.03). On the other hand, the carotenoids content was slightly affected either by drought stress or bacterial inoculation and their highest content was recorded in the $B_{2}$-inoculated-unstressed seedlings $(3.3 \mathrm{mg} / \mathrm{g}$ $\mathrm{DM}$ ), while the least content was recorded in the $\mathrm{B}_{1}$-inoculated-drought-stressed ones $(2.3 \mathrm{mg} / \mathrm{g} \mathrm{DM})$.

\section{Membrane leakage, hydrogen peroxide and malondialdehyde}

Growing wheat seedlings without water for 7 days significantly increased the leakage of electrolytes and the accumulation of $\mathrm{H}_{2} \mathrm{O}_{2}$ and MDA in the leaves of all treatments (Fig. 4). The highest membrane damage, which was indicated by the electrolyte leakage was determined in the uninoculated-drought-stressed seedlings (D), which was 9.3 fold of the uninoculated-unstressed control. On the other hand, the leaves of the inoculated-drought-stressed seedlings showed significantly lower leakage of electrolytes and the lowest leakage was recorded in the stressed seedlings inoculated with $B_{1}$ which was about $46 \%$ lower than that of the stressed-uninoculated counterparts (D). Similarly, bacterial inoculation with both strains notably decreased the accumulation of $\mathrm{H}_{2} \mathrm{O}_{2}$ and MDA in the leaves of wheat seedlings under drought stress without significant differences between them. The least amounts of $\mathrm{H}_{2} \mathrm{O}_{2}$ and MDA under drought stress were recorded in the $\mathrm{DB}_{1}$ which were 9.1 and $0.98 \mu \mathrm{mole} / \mathrm{g} \mathrm{FM}$, compared with 22 and $1.6 \mu$ mole/g FM, respectively, in the D treatments.

\section{Ascorbic acid and proline}

The drought stress resulted in a significant decrease of Ascorbic acid (A.A) content by about 53\%, compared with the well-irrigated control, while this decrease was only $38 \%$ and $41 \%$ in the A. brasilense and S. maltophilia -treated seedlings, respectively (Fig. 5). Under the wellirrigated conditions, the effects of both strains were opposite to each other: while S. maltophilia induced the highest accumulation of A.A in leaves ( $71 \mathrm{mg} / \mathrm{g}$ DM), $A$. brasilense significantly decreased its content to $\sim 55$ ( $\mathrm{mg} / \mathrm{g} \mathrm{DM})$, where in the bacteria-free control, the value was $62.9(\mathrm{mg} / \mathrm{g} \mathrm{DM})$. 

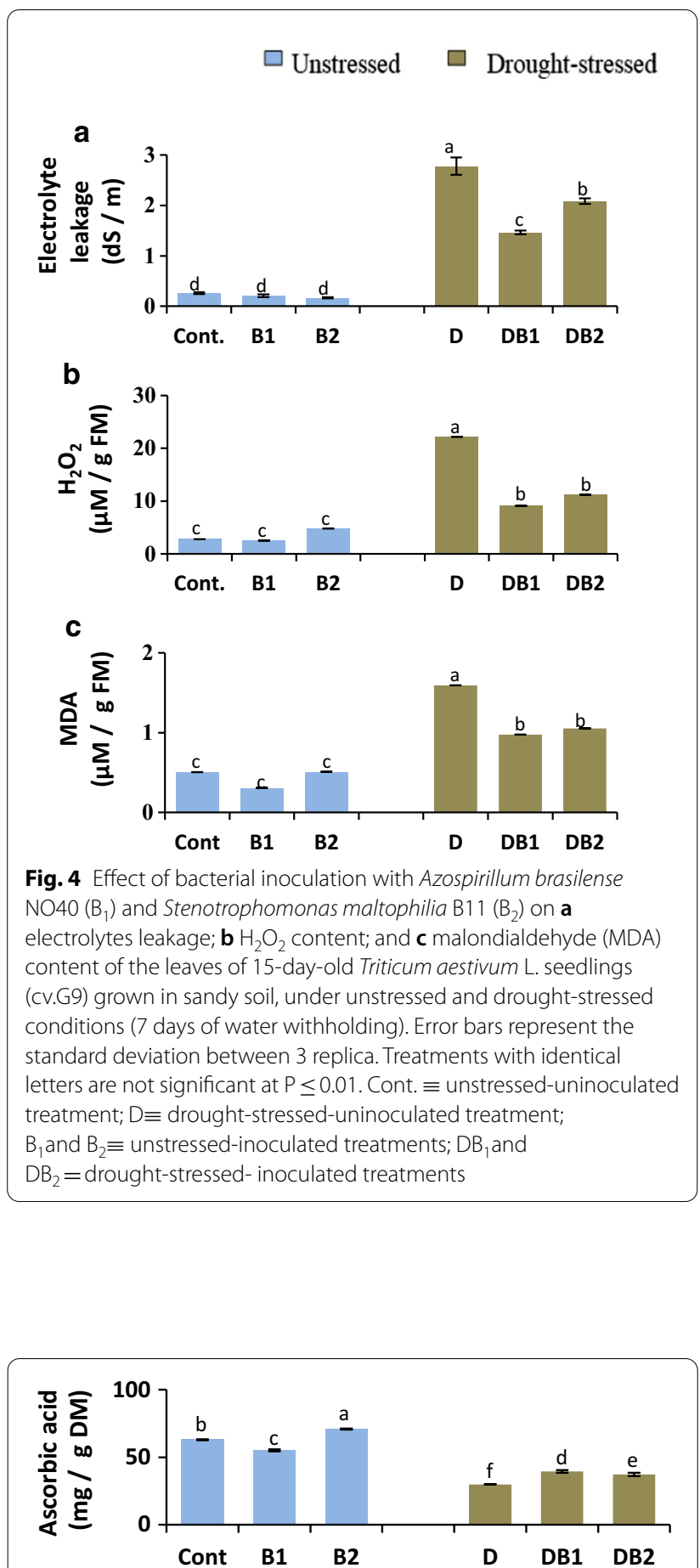

Fig. 5 Effect of bacterial inoculation with Azospirillum brasilense NO40 $\left(B_{1}\right)$ and Stenotrophomonas maltophilia B11 $\left(B_{2}\right)$ on the content of ascorbic acid in the leaves of 15-day-old Triticum aestivum $\mathrm{L}$. seedlings (cv. G9) grown in sandy soil, under unstressed and drought stressed conditions (7 days of water withholding). Error bars represent the standard deviation between 3 replica. Treatments with identical letters are not significant at $P \leq 0.01$. Cont. $\equiv$ unstressed-uninoculated treatment; $D \equiv$ drought-stressed-uninoculated treatment;

$\mathrm{B}_{1}$ and $\mathrm{B}_{2} \equiv$ unstressed-inoculated treatments; $\mathrm{DB}_{1}$ and $\mathrm{DB}_{2}=$ drought-stressed-inoculated treatments
The exposure of the uninoculated seedlings to 7 days of water withholding significantly elevated their content of proline in the roots and shoots by about 3 and 10 folds, respectively, relative to the uninoculated-unstressed control (Fig. 6). On the other hand, inoculating seedlings with $B_{1}$ and $B_{2}$ significantly reduced the accumulation of proline under drought stress. In roots, the effect of both strains was similar, where the proline content of the stressed roots was $\geq 20 \%$ less than that in the uninoculated-drought- stressed ones. In shoots, the influence of both strains was variable; where under stress conditions, the inoculation with $S$. maltophilia decreased the proline content by $\sim 47 \%$, while the decrease was only $31 \%$ in case of $B_{1}$, compared with the uninoculated-stressed counterparts (D). In the unstressed wheat seedlings, both strains had non-significant effect on the proline content in their roots or shoots.

\section{Antioxidant enzymes}

Figure $7 a-d$ showed that drought stress significantly promoted the activities of catalase and peroxide in roots and shoots. The highest catalase activities were recorded in the uninoculated-stressed seedlings (D), which were $0.18 \mu \mathrm{mole} / \mathrm{g} \mathrm{FM} / \mathrm{min}$ in roots and $0.36 \mu$ mole /g FM / $\mathrm{min}$ in shoots. Likewise, in D treatment, peroxidase activities were enhanced by about 4 and 3 folds in roots and shoots, respectively. However, the application of any

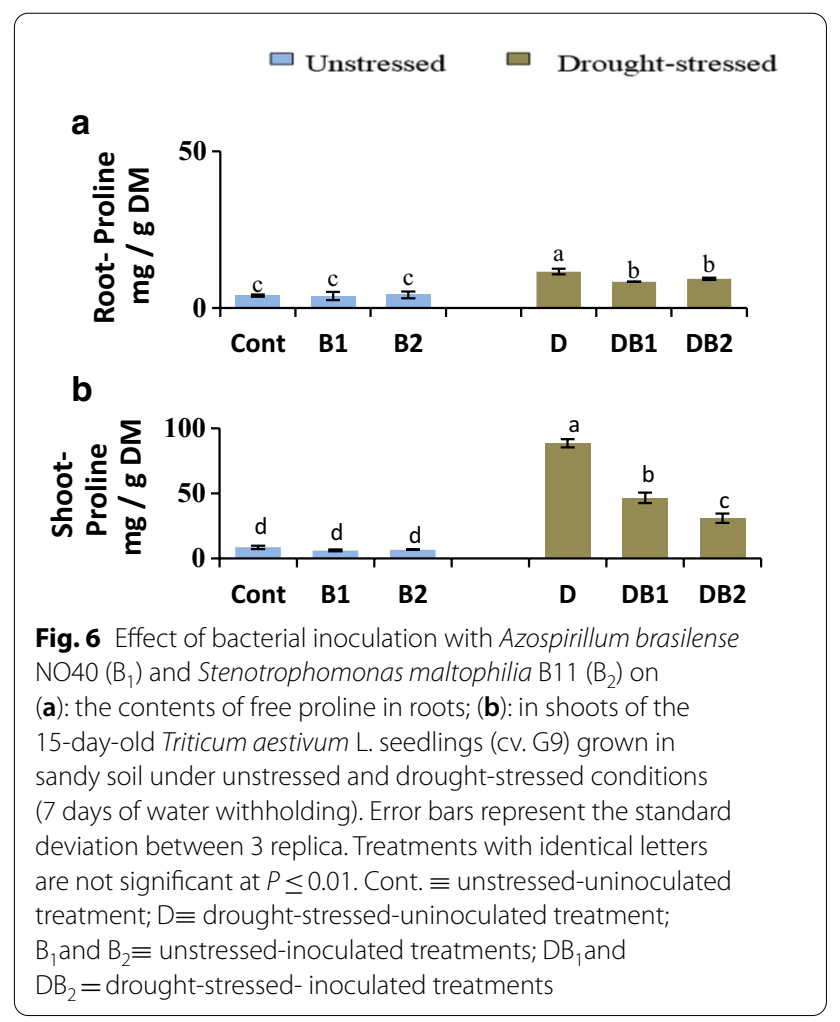


$\square$ Unstressed $\square$ Drought-stressed

a

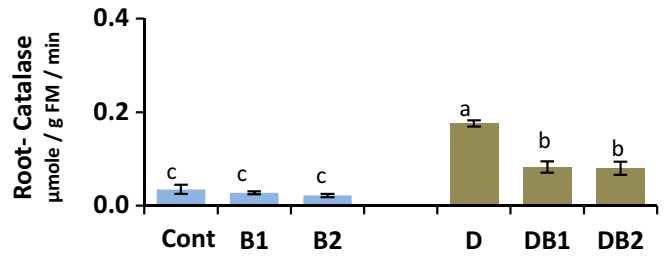

C

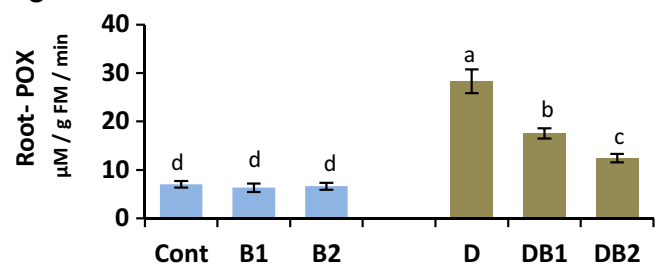

b

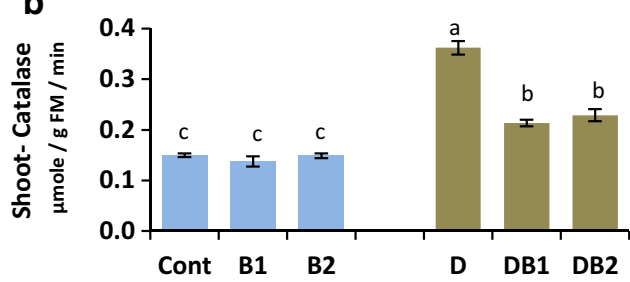

d

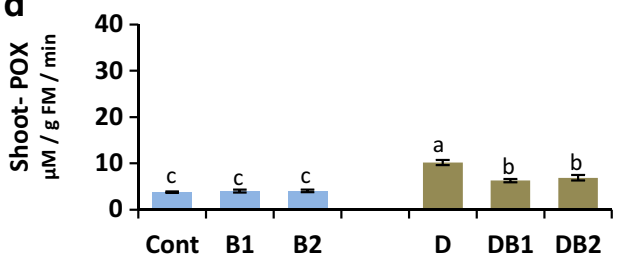

Fig. 7 Effect of bacterial inoculation with Azospirillum brasilense NO40 $\left(B_{1}\right)$ and Stenotrophomonas maltophilia B11 $\left(B_{2}\right)$ on a catalase activity of roots; $\mathbf{b}$ catalase activity of shoots; $\mathbf{c}$ peroxidase activity of roots; $\mathbf{d}$ peroxidase activity of shoots of the 15-day-old Triticum aestivum $\mathrm{L}$. seedlings (cv. G9) grown in sandy soil, under unstressed and drought stressed conditions (7 days of water withholding). Error bars represent the standard deviation between 3 replica. Treatments with identical letters are not significant at $P \leq 0.01$. Cont. $\equiv$ unstressed-uninoculated treatment; $D \equiv$ drought-stressed-uninoculated treatment; $\mathrm{B}_{1}$ and $\mathrm{B}_{2} \equiv$ unstressed-inoculated treatments; $\mathrm{DB}_{1}$ and $\mathrm{DB}_{2}=$ drought-stressed-inoculated treatments

of the two strains inhibited the catalase activity in $\mathrm{DB}_{1}$ and $\mathrm{DB}_{2}$ by about $56 \%$ in roots and $\geq 36 \%$ in shoots, in respect with their uninoculated-stressed counterparts (D). Moreover, the $B_{1}$ and $B_{2}$-inoculated-stressed wheat seedlings had less activities of peroxidase by 38 and $56 \%$ in roots and by 38 and $32 \%$ in shoots, respectively, than their D counterparts.

\section{SDS-PAGE of root protein}

The results showed that both of drought stress and bacterial inoculation caused several changes in the protein patterns of root of wheat seedlings (Table 2) as follow:

- The drought stress induced synthesis of new stress proteins bands with MM 138, 89, 47 and $25 \mathrm{kDa}$, which were not detected in all of the inoculatedstressed seedlings, as the bands having MM 138, 89 and $47 \mathrm{kDa}$ disappeared B1-stressed treatment $\left(\mathrm{DB}_{1}\right)$ while the $25 \mathrm{kDa}$ band disappeared in the $\mathrm{B} 2$-stressed treatment $\left(\mathrm{DB}_{2}\right)$,

- Four polypeptides having MM 144, 94, 82 and $27 \mathrm{kDa}$ were detected in the control but they disappeared in all of the drought-stressed treatments, and

- The bacterial inoculation resulted in the appearance of four new synthesized protein bands under drought stress with MM $125 \mathrm{kDa}$ with $\mathrm{DB}_{1} ; 74$ and $51 \mathrm{kDa}$ with both $\mathrm{DB}_{1}$ and $\mathrm{DB}_{2}$; and $26 \mathrm{kDa}$ with $\mathrm{DB}_{2}$, all of them were not detected in the control or in the corresponding uninoculated-drought-stressed counterparts (D).

\section{Discussion}

Upon exposure to drought stress, plants actively reprogram their metabolism and growth in order to limit damage and facilitate the recovery of impaired systems (Farooq et al. 2009; Claeys and Inze 2013). However, the key challenge for plants is to balance between growth and survival to maintain the best yields as they can (Claeys and Inze 2013). The current study investigated the possible contribution of PGPB to this balance.

The onset of drought stress without bacterial inoculation during the seedling stage resulted in significant reductions in the leaf area, which has been repeatedly recorded in many studies (Farooq et al. 2009; Bhargava and Sawant 2013). Under drought stress, plants tend to limit their shoot growth in order to reduce the evaporation surface and thereby their water balance and survival can be enhanced (Bhargava and Sawant 2013; Claeys and Inze 2013). The shoot growth limitation occurs directly by reducing the water uptake, resulting in the loss of cell turgor which in turn inhibits the cell elongation and expansion; and indirectly by closing stomata resulting in lowered rates of nutrient uptake and photo-assimilation, which in turn reduces the metabolites and energy required for cell division (Farooq et al. 2009; Bhargava and Sawant 2013).

On the other hand, the inoculated seedlings with $A$. brasilense or S. maltophilia had significantly enhanced leaf area and generally healthier phenotypes (i.e. less wilting symptoms than their uninoculated counterparts). These results are in harmony with those obtained for $A$. 
Table 2 Changes in the molecular masses of protein bands as revealed by SDS-PAGE of the protein of roots of 15-day-old Triticum aestivum L. seedlings grown in sandy soil, under unstressed and drought stressed (7 days of water withholding) conditions, with and without inoculation with Azospirillum brasilense NO40 $\left(\mathrm{B}_{1}\right)$ and Stenotrophomonas maltophilia B11 ( $\left.\mathrm{B}_{2}\right)$

\begin{tabular}{|c|c|c|c|c|c|c|c|}
\hline $\mathrm{M}(\mathrm{KDa})$ & $\mathrm{MM}(\mathrm{KDa})$ & Cont & $\mathrm{B}_{1}$ & $B_{2}$ & D & $\mathrm{DB}_{1}$ & $\mathrm{DB}_{2}$ \\
\hline \multirow[t]{7}{*}{250} & & - & - & - & - & - & - \\
\hline & 147 & - & + & - & - & - & - \\
\hline & 144 & + & - & - & - & - & - \\
\hline & 141 & - & - & + & - & - & - \\
\hline & 138 & - & - & - & + & - & - \\
\hline & 133 & - & - & - & - & + & - \\
\hline & 125 & - & - & - & - & - & + \\
\hline \multirow[t]{4}{*}{130} & & - & - & - & - & - & - \\
\hline & 94 & + & + & + & - & - & - \\
\hline & 91 & - & - & - & - & + & - \\
\hline & 89 & - & - & - & + & - & + \\
\hline \multirow[t]{4}{*}{95} & & - & - & - & - & - & - \\
\hline & 82 & + & - & - & - & - & - \\
\hline & 80 & - & + & + & + & - & - \\
\hline & 74 & - & - & - & - & + & + \\
\hline \multirow[t]{5}{*}{72} & & - & - & - & - & - & - \\
\hline & 54 & - & - & + & - & - & - \\
\hline & 53 & - & + & - & - & - & - \\
\hline & 52 & + & - & - & + & - & - \\
\hline & 51 & - & - & - & - & + & + \\
\hline \multirow[t]{4}{*}{55} & & - & - & - & - & - & - \\
\hline & 48 & + & - & + & - & + & - \\
\hline & 47 & - & + & - & + & - & + \\
\hline & 40 & + & + & + & + & + & + \\
\hline \multirow[t]{2}{*}{36} & & - & - & - & - & - & - \\
\hline & 35 & + & + & + & + & + & + \\
\hline \multirow[t]{4}{*}{28} & & - & - & - & - & - & - \\
\hline & 27 & + & - & - & - & - & - \\
\hline & 26 & - & + & + & - & - & + \\
\hline & 25 & - & - & - & + & + & - \\
\hline
\end{tabular}

$\mathrm{M}=$ marker; $\mathrm{MM}=$ molecular mass; $+=$ present, $-=$ absent; Cont. = unstressed-uninoculated treatmentl; $\mathrm{D}=$ drought-stressed-uninoculated treatment; $\mathrm{B}_{1}$ and $\mathrm{B}_{2}=$ unstressed-inoculated treatments; $\mathrm{DB}_{1}$ and $\mathrm{DB}_{2}=$ drought-stressed-inoculated treatments

brasilense- inoculated wheat exposed to either to drought (Kasim et al. 2013); heat (Abd El-Daim et al. 2014) or cold (Osman et al. 2014). Singh and Jha (2017) indicated that S. malthopilia SBP-9 has the potential to promote wheat growth under salt stress, while S. malthopilia MGT18 (endophytic selenobacteria) improved soybean growth under drought stress (Trivedi et al. 2019). Omar et al. (2017) reported that both of $A$. brasilense and S. maltophilia possess several plant growth promoting traits that may; (1) assist in better availability of nutrients such as $\mathrm{N}_{2}$ and $\mathrm{P}$ by fixing atmospheric $\mathrm{N}_{2}$ and solubilizing the inorganic P (Ahemad and Kibret 2014); and (2) modulate the plant hormones level either by synthesizing IAA, $\mathrm{GA}_{3}$ and $\mathrm{ABA}$ or by lowering the plant-produced ethylene via the ACC-deaminase activity, all of which are known as signals that affect the plant morphogenetic processes (Potters et al. 2007). This in addition to the possibility of having other plant growth promoting traits such as production of exopolysachharides (Kasim et al. 2016; An and Berg 2018).

Unsurprisingly, the limited water supply resulted in a massive decline in the measured relative water contents in all organs, which indicates the water status of the tissues, and in turn reflects the stress severity as stated by Reddy et al. (2004). Thus, based on the dramatically declined values of RWCs, it seems fair to suggest that the uninoculated wheat seedlings exhibited relatively low tolerance to the imposed drought stress, especially with the 
obvious wilting symptoms, compared to the inoculated seedlings that showed significantly augmented values of RWCs accompanied with healthier phenotypes. The correlation between the increased RWC with PGPB application has been recorded in several plants under drought stress (Kasim et al. 2013; Naveed et al. 2014; Trivedi et al. 2019). Cohen et al. (2015) attributed these findings, in part, to the better control of stomata closure mediated by produced $A B A$, in addition to the enhanced water uptake that may have resulted from the enhanced root length and lateral roots number induced by the bacterial IAA and GA. However, Timmusk et al. (2014) indicated that bacterial inoculation significantly enhanced root hair and lateral roots formation, especially under drought stress, but without increasing the total root dry mass or the main root length. Accordingly, it can be suggested that A. brasilense and S. maltophilia may have helped the drought-stressed wheat plants to attain higher RWCs by inducing better control of stomata and by mediating alternations in root architecture.

The water status deterioration of the uninoculatedstressed seedlings was recorded despite the significantly elevated contents of proline in their roots and shoots. This may imply that the accumulated proline was not enough to reduce the cell osmotic potential, and therefore to maintain sufficient cell turgor. Shabala and Shabala (2011) questioned the direct contribution of organic osmolytes to the maintenance of cell turgor, suggesting that the organic osmolytes have a slight quantitative contribution to the osmotic adjustment, but they may mainly act as low-molecular-weight chaperones in maintaining the membranes'integrity; protecting the structure of enzymes and proteins; protecting and repairing of PSII and buffering the redox potential, however, none of these roles require a substantial accumulation of osmolytes to have a beneficial effect. Furthermore, these authors stated that the energy cost of organic osmolytes production is at least 10 times higher than that of inorganic ion uptake. Also, they referred to many studies where the salt-sensitive genotypes accumulated much more organic osmolytes like proline and glycine betaine compared with the tolerant ones, by which they consumed about 4.5 times more ATP than the tolerant genotypes that resulted in severe yield penalties at the end. However, this hypothesis was contradicted by the findings of Hummel et al. (2010), which indicated that the organic part of the osmotic adjustment (OA) represents a low cost compared with the other carbon fluxes, mainly because of the fact that growth is inhibited more than and before photosynthesis under water deficit. In accordance, Blum (2011) proposed that since the leaf expansion is arrested by drought stress before leaf photosynthesis is inhibited, some of the photosynthates that have been normally used for leaf expansion are now available for either OA or root growth. This may imply that $\mathrm{OA}$ is a result of the growth inhibition not a cause. But in general, it can be concluded that accumulating high proline content was not necessary and may be it was unwise use of resources.

In the same context, the uninoculated wheat seedlings had markedly enhanced activities of catalase. Such response has been widely recorded in many droughtstressed plants such as barely (Harb et al. 2015) and wheat (Wei et al. 2013) as they play an important role in the fine regulation of reactive oxygen species in the cell through activation and deactivation of $\mathrm{H}_{2} \mathrm{O}_{2}$ (Sairam et al. 2005). However, there are conflicting reports about relating the enhanced activities of antioxidant enzymes with tolerance, where some tolerant genotypes of wheat (Sairam et al. 1998) and tobacco (Su et al. 2017) showed higher activities of antioxidant enzymes than the drought-sensitive ones, while in the study of Wei et al. (2013) on PEG6000-stressed wheat seedlings, the antioxidant enzymes activities were higher in the droughtsensitive cultivar than in the tolerant one. This suggests that the contribution of the antioxidant enzymes to plant tolerance is variable and cannot be only concluded from the elevated activities, but from the overall performance of plants.

On the other hand, the inoculated-drought-stressed seedlings had less pronounced defense, indicated by lower catalase and peroxidase activities and proline content. Similar results were also recorded in plants inoculated with $A$. brasilense NO40: for example in barely under salt stress (Omar et al. 2009) where the inoculated seedlings had significantly reduced contents of proline and activities of catalase and peroxidase in their shoots and roots; and in wheat under progressive drought stress (Kasim et al. 2013) where the primed seedlings had significantly lower activities of ascorbate peroxidase, while Singh and Jha (2017) found that the salt-stressed wheat plants inoculated with S. maltophilia SBP-9 had decreased content of proline, but elevated activities of superoxide dismutase, catalase, and peroxidase. The generally less activated defenses of the inoculated wheat seedlings after imposing drought for 7 days, may imply that these inoculated seedlings either sense less degree of drought stress by which higher activation of defenses were no longer needed; or they exhibited a higher degree of drought tolerance than that of the uninoculated ones.

Under drought stress, plants also tend to enhance the production of antioxidants like ascorbic acid and carotenoids in order to minimize the detrimental effects of oxidative stress and normalize their metabolic activities (Dar et al. 2017). The current study indicated that the carotenoids content was slightly affected by drought stress and inoculation. The influence of water stress on carotenoids 
greatly varied, it may be increased (Guha et al. 2010); decreased (Emami Bistgani et al. 2017) or unchanged (Nikolaeva et al. 2017) and highly dependent on the plant genotype (Nikolaeva et al. 2017); stress severity (Nikolaeva et al. 2017) and duration (Chakraborty et al. 2013), rather than any additional treatments (Askari and Ehsanzadeh 2015), including bacterial inoculation (Chakraborty et al. 2013), which explain why the carotenoids content was slightly affected either by drought stress or bacterial inoculation in this study.

Regarding the ascorbic acid (A.A), the current results show that the A.A content was significantly declined in the leaves of the uninoculated-drought-stressed seedlings by about $53 \%$, compared with the well-irrigated control. Selote and Khanna-Chopra (2004) found that A.A and reduced glutathione contents in rice panicles were enhanced after the initiation of stress and maintained the same levels lasting for about 3 days, but decreased on a longer timeframe of 5 consecutive days of stress, indicating that the drought tolerance is not only related to enhanced antioxidant system, but also to a similar extent to the rate of decline of the system (Guo et al. 2006). The drought-induced decline in ascorbate levels was also observed in the leaves of wheat (Bartoli et al. 1999) and in leaves and stems of soybean (Seminario et al. 2017). The reduced level of A.A may be related to its reduced biosynthesis (Seminario et al. 2017), or to the possible partial influence of the reduced photosynthates' supply (Conklin 2001). On the other hand, the inoculated-droughtstressed plants had higher A.A levels than those in the uninoculated counterparts. The PGPB-induced increase in A.A was also recorded in wheat plants inoculated with Bacillus safensis or Ochrobactrum pseudogregnonense under drought (Chakraborty et al. 2013) and heat stress (Sarkar et al. 2018). The increase in A.A may be a result of its enhanced biosynthesis and recycling which mainly related to the enhanced enzymes' activities (Seminario et al. 2017); to the PGPB-diminished reduction in leaf dehydration; and may be partially due to the altered photosynthate supply (Conklin, 2001), where all of them can be affected by the PGPB metabolites.

As the results revealed, drought stress induced substantial damage in the uninoculated seedlings, as manifested by the significant increase in the leakage of electrolytes, accumulation of MDA and $\mathrm{H}_{2} \mathrm{O}_{2}$. Upon exposure to drought stress, most plants close their stomata to control water loss (Pirasteh-Anosheh et al. 2016) which results in limited intake and assimilation of $\mathrm{CO}_{2}$, reduced $\mathrm{NADP}^{+}$regeneration, increased leakage of electrons to $\mathrm{O}_{2}$, enhanced photorespiration and finally to augmented ROS formation (Dar et al. 2017). This augmented ROS formation functions as an alarm signal that triggers acclimatory/defense responses if kept at an appropriate level by adequate scavenging, but if their formation overwhelms their scavenging, oxidative stress occurs, where the over-accumulated ROS can impose significant damage by reacting with different cellular components (Dar et al. 2017; Mittler 2017). Therefore, the boosted $\mathrm{H}_{2} \mathrm{O}_{2}$ content in leaves of the uninoculatedstressed wheat seedlings reflects a higher degree of oxidative stress and hence a greater damage, confirmed by the elevated values of MDA and membrane leakage. $\mathrm{H}_{2} \mathrm{O}_{2}$ at high concentrations, has the potential to react with proteins by attacking their cysteine and methionine residues; inactivate enzymes by oxidizing their thiol groups; react with DNA molecules; induce programmed cell death; and to be transformed into more reactive and toxic species like $\mathrm{OH}^{*}$ (Dar et al. 2017; Mittler 2017), while MDA is one of the final products of the peroxidation of the unsaturated fatty acids in the phospholipids bilayer (Sharma et al. 2012). The lipid peroxidation is considered to be one of the most damaging processes in all living organisms (Gill and Tuteja 2010), in which the ROS attack the double bond between two carbon atoms and the ester linkage between glycerol and fatty acids in the phospholipid bilayer resulting in damaging products like MDA (Sharma et al. 2012). These products can react with and damage proteins and DNA, in addition to their basic interference with the stability of cellular and organellar membranes where they diminish fluidity, which is detrimental to membranes' functional structure leading to increased electrolytes' leakage as found in the present results (Farooq et al. 2009; Dar et al. 2017). The enhanced values of electrolytes' leakage further confirm the drought-mediated injury to the cellular membranes, which may be not only resulted from lipid peroxidation, but also from the protoplasm shrink, crowding and viscosity increase, proteins displacement and denaturation, increased rigidity and induced mechanical stress, all of which negatively affect the membranes' intactness and permeability under water deficit (Farooq et al. 2009; Dar et al. 2017).

In contrast, the inoculated seedlings showed less susceptibility to the drought-mediated damage as they accumulated notably fewer contents of $\mathrm{H}_{2} \mathrm{O}_{2}$ and MDA and displayed reduced electrolytes' leakage in their leaves. These results are in accordance with those of GontiaMishra et al. (2016) on wheat, who suggested that the inoculated seedlings did not encounter much stress and therefore, exhibited higher membrane stability. Singh and Jha (2017) also reported that treating plants with bacterium possessing multi growth-promoting traits (e.g. ACC-deaminase, IAA, GA and ammonia production) was able to counteract the inhibitory effects of salt stress.

The results reveal notable retardation in the contents of chl-a and $b$ in the drought-stressed wheat leaves. This 
retardation can be attributed to different reasons such as: (1) impaired biosynthesis and/or accelerated degradation of chl., (Ashraf and Harris 2013); (2) enhanced synthesis of nitrogen compounds such as proline, which consumes a large amount of nitrogen, as suggested by De La RosaIbarra and Maiti (1995); and (3) the injured photosynthetic membranes, as indicated by Kasim et al. (2014). Meanwhile, bacterial inoculation significantly reversed the negative effects of drought stress on the contents of chl-a and chl-b, especially in the seedlings treated with $S$. maltophilia. Cohen et al. (2015), suggested that the stimulation of photosynthetic pigments and reduction in the MDA content in the drought-stressed Arabidopsis inoculated with $A$. brasilense Sp 245 can be attributed to the augmented ABA content resulting from the association of the ABA produced in the drought-stressed plants, with the ABA- produced by the bacteria which might have prepared the plant to cope better with unfavorable environmental conditions.

Proteins are the principal molecules responsible for energy production, structural organization, cell communications, cell signaling, and cell division; therefore, plants reprogram their assembly to tolerate drought stress (Jha and Subramanian, 2018). In this study, some new stress protein bands were induced by drought stress with MM 138, 89, 47 and 25 KDa which were not detected in all of the inoculated-drought stressed seedlings. The band has $138 \mathrm{kDa}$ might act as a member of HSP 100 and the unique function of this class is the reactivation of aggregated proteins (Parsell andLindquist 1993), helping to degrade irreversibly damaged polypeptides (Al-Whaibi, 2011) and facilitating the normal situation of the organism after severe stress (Gurley, 2000). The appeared $89 \mathrm{kDa}$ band may function as HSP 90, that regulates protein folding (Efeoglu 2009), plays a key role in signal transduction, and helps in protein degradation and transferring (Park and Seo, 2015). Meanwhil, the appeared $47 \mathrm{kDa}$ band may function as HSP 40 known to increase HSP 70 affinity for clients (Kampinga and Craig, 2010). Moreover, the newly synthesized $25 \mathrm{kDa}$ probably belongs to the wide ranged small heat shock proteins (sHSPs) where their MM ranges from 15 to $42 \mathrm{kDa}$ (Zhang et al. 2015), they could play an important role in the maintenance of membrane integrity under stress conditions (Haq et al. 2013). Bacterial inoculation resulted in the appearance of four new synthesized protein bands under drought stress with MM 125, 74, 51 and $26 \mathrm{kDa}$, all of which were not detected in the control or in the corresponding uninoculated-drought-stressed counterparts. The obtained variation between the inoculated and uninoculated seedlings may assure that PGPB can modulate protein synthesis to harness the plant growth under drought stress.

\section{Conclusions}

By comparing the attained damage (the electrolytes' leakage, and accumulation of MDA and $\mathrm{H}_{2} \mathrm{O}_{2}$ ) with the generally elevated defenses (higher proline content and enhanced activities of CAT and POX enzymes) in the drought-stressed wheat seedlings, in the presence and absence of the PGPB, it denotes that- despite the highly activated defenses, the drought stress was extremely damaging for the uninoculated wheat seedlings, unlike the inoculated ones that had notably reduced damage in spite of their less enhanced but probably more efficient defenses that had saved more resources to maintain better growth. Therefore, it can be concluded that both Azospirillum brasilense NO40 and Stenotrophomonas maltophilia B11 were able to reduce the growth inhibition to some extent while they maintain a certain level of efficient protection against damage, in other words, they notably helped the wheat seedlings to reach a considerable balance between survival and growth under drought stress.

\begin{abstract}
Abbreviations
A. A: Ascorbic acid; ABA: Abscisic acid; A. brasilense NO40: Azospirillum brasilense NO40; ACC: 1-Amino-cyclopropane-1-carboxylate; ANOVA: Analysis of variance; ATP: Adenosine tri-phosphate; Chl: Chlorophyll; CFU: Colony forming unit; cv.: Cultivar; D: Drought-stressed; DM: Dry mass; FM: Fresh mass; G9: Gemiza 9; GA3: Gibberellic acid; HSP: Heat shock proteins; IAA: Indole acetic acid; LA: Leaf area; LPO: Lipid peroxidation; LRWC: Leaf relative water content; LSD: Least significance difference; MDA: Malondialdehyde; NADP: Nicotinamide adenine dinucleotide phosphate; OA: Osmotic adjustment; OD: Optical density; PEG6000: Poly-ethylene glycol 6000; PGPB: Plant growth promoting bacteria; POX: Peroxidase; ROS: Reactive oxygen species; RWC: Relative water content; SDS: Sodium dodecyl sulphate; SFC: Soil field capacity; S. maltophilia B11: Stenotrophomonas maltophilia B11.
\end{abstract}

\section{Acknowledgements}

We dedicate this work to the soul of Prof. Dr. Wedad Abdel-Aziz Kasim: we honestly value the time, effort and energy you have generously dedicated to this work (planning, following up, revising...etc.) and for the insights we gained through dealing with you.

\section{Authors' contributions}

WK: Work design, manuscript writing and revision. MEHO: Work design and manuscript revision. MNO: Work design and manuscript revision. SS: Work design, experiments conducting, data interpretation and manuscript writing. All authors have read and approved the manuscript.

\section{Funding}

"Not applicable"; this work did not receive any especial fund.

\section{Availability of data and materials}

Data and materials of the current study are available from the corresponding author on reasonable request.

\section{Declarations}

Ethics approval and consent to participate Not applicable.

Consent for publication

Not applicable. 


\section{Competing interests}

The authors declare that they have no competing interests.

\section{Author details}

${ }^{1}$ Botany Department, Faculty of Science, Tanta University, Tanta, Egypt. ${ }^{2}$ Microbiology Department, Soils, Water and Environment Research Instiute, Agriculture Research Centre, Giza, Egypt.

Received: 26 February 2021 Accepted: 20 April 2021 Published online: 20 May 2021

\section{References}

Abd El-Daim IA, Bejai S, Meijer J (2014) Improved heat stress tolerance of wheat seedlings by bacterial seed treatment. Plant Soil 379:337-350. https://doi.org/10.1007/s11104-014-2063-3

Ahemad M, Kibret M (2014) Mechanisms and applications of plant growth promoting rhizobacteria: current perspective. J King Saud Univ Sci 26:1-20. https://doi.org/10.1016/j.jksus.2013.05.001

Al-Whaibi MH (2011) Plant heat-shock proteins: a mini review. J King Saud Univ Sci 23:139-150. https://doi.org/10.1016/j.jksus.2010.06.022

An S, Berg G (2018) Stenotrophomonas maltophilia. Trends Microbiol 26:637-638. https://doi.org/10.1016/j.tim.2018.04.006

Arnon D (1949) Copper enzymes in isolated chloroplasts: polyphenol oxidase in Beta vulgaris. Plant Physiol 24:1-15. https://doi.org/10.1104/pp.24.1.1

Ashraf M, Harris PJC (2013) Photosynthesis under stressful environments: an overview. Photosynthetica 51:163-190. https://doi.org/10.1007/ s11099-013-0021-6

Askari E, Ehsanzadeh P (2015) Drought stress mitigation by foliar application of salicylic acid and their interactive effects on physiological characteristics of fennel (Foeniculum vulgare Mill.) genotypes. Acta Physiol Plant 37:1-14. https://doi.org/10.1007/s11738-014-1762-y

Bartoli CG, Simontacchi M, Tambussi E, Beltrano J, Montaldi E, Puntarulo S (1999) Drought and watering-dependent oxidative stress: effect on antioxidant content in Triticum aestivum L. leaves. J Exp Bot 50:375-383. https://doi.org/10.1093/jxb/50.332.375

Bates LS, Waldren RD, Teare ID (1973) Rapid determination of free proline for water stress studies. Plant Soil 39:205-207. https://doi.org/10.1007/BF000 18060

Beauchamp C, Fridovich I (1971) Superoxide dismutase improved assays and an assay applicable to acrylamide gels. Anal Biochem 44:276-287. https:// doi.org/10.1016/0003-2697(71)90370-8

Bhargava S, Sawant K (2013) Drought stress adaptation: metabolic adjustment and regulation of gene expression. Plant Breed 132:21-32. https://doi org/10.1111/pbr.12004

Blum A (2011) Drought resistance and its improvement. In: Blum A (ed) Plant breeding for water-limited environments. Springer, New York, pp 53-152

Bodner G, Nakhforoosh A, Kaul HP (2015) Management of crop water under drought: a review. Agron Sustain Dev 35:401-442. https://doi.org/10. 1007/s13593-015-0283-4

Chakraborty U, Chakraborty BN, Chakraborty AP, Dey PL (2013) Water stress amelioration and plant growth promotion in wheat plants by osmotic stress tolerant bacteria. World J Microbiol Biotechnol 29:789-803. https:// doi.org/10.1007/s11274-012-1234-8

Claeys H, Inze D (2013) The agony of choice: how plants balance growth and survival under water-limiting conditions. Plant Physiol 162:1768-1779. https://doi.org/10.1104/pp.113.220921

Cohen AC, Bottini R, Pontin M, Berli FJ, Moreno D, Boccanlandro H, Travaglia CN, Piccoli PN (2015) Azospirillum brasilense ameliorates the response of Arabidopsis thaliana to drought mainly via enhancement of ABA levels. Physiol Plant 153:79-90. https://doi.org/10.1111/ppl.12221

Conklin PL (2001) Recent advances in the role and biosynthesis of ascorbic acid in plants. Plant Cell Environ 24:383-394. https://doi.org/10.1046/j. 1365-3040.2001.00686.x

Dar MI, Naikoo MI, Khan FA, Rehman F, Green ID, Naushin F, Ansari AA (2017) An introduction to reactive oxygen species metabolism under changing climate in plants. In: Khan MIR, Khan NA (eds) Reactive oxygen species and antioxidant systems in plants: role and regulation under abiotic stress. Springer, Singapore, pp 25-52
De La Rosalbarra M, Maiti RK (1995) Biochemical mechanism in glossy sorghum lines for resistance to salinity stress. J Plant Physiol 146:515-519. https://doi.org/10.1016/S0176-1617(11)82017-1

Efeoglu B (2009) Heat shock proteins and heat shock response in plants. G U J 22(2):67-75

El-Shami MEM, Abdel-karim AA, Hanna NS, Towfelis MB, Tammam AM, Gedan MK, AbdelAleem MM, Menshawy AM, Ashoush HA (2000) Gemmiza 9: a new Egyptian high yielding and rust resistant bread wheat cultivar for Delta region. J Agric Sci Mansoura Univ 25:7407-7419

Emami Bistgani Z, Siadat SA, Bakhshandeh A, Ghasemi Pirbalouti A, Hashemi M (2017) Interactive effects of drought stress and chitosan application on physiological characteristics and essential oil yield of Thymus daenensisCelak. Crop J 5:407-415. https://doi.org/10.1016/j.cj.2017.04.003

Fan X, Hu H, Huang G, Huang F, Li Y, Palta J (2015) Soil inoculation with Burkholderia sp. LD-11 has positive effect on water use efficiency in inbred lines of maize. Plant Soil 390:337-349. https://doi.org/10.1007/ s11104-015-2410-z

FAO (2003) A contribution to "Water for people- Water for life, the United Nations World Water Development Report @UNESCO-WWAP 2003. https://pre.pdf-read.com/agriculture-food-and-water/6054737.html

Farooq M, Wahid A, Kobayashi N, Fujita D, Basra SMA (2009) Plant drought stress: effects, mechanisms and management. Agron Sustain Dev 29:185-212. https://doi.org/10.1051/agro:2008021

Figueiredo MVB, Bonifacio A, Rodrigues AC, de Araujo FF (2016) Plant growthpromoting rhizobacteria: key mechanisms of action. In: Choudhary DK, Varma A (eds) Microbial-mediated induced systemic resistance in plants. Springer, Singapore, pp 23-37

Gill SS, Tuteja N (2016) Reactive oxygen species and antioxidant machinery in abiotic stress tolerance in crop plants. Plant Physiol Biochem 48:909-930. https://doi.org/10.1016/j.plaphy.2010.08.016

Gontia-Mishra I, Sapre S, Sharma A, Tiwari S (2016) Amelioration of drought tolerance in wheat by the interaction of plant growth promoting rhizobacteria. Plant Biol 18:992-1000. https://doi.org/10.1111/plb.12505

Goswami M, Deka S (2020) Plant growth-promoting rhizobacteria-alleviators of abiotic stresses in soil: a review. Pedosphere 30(1):40-61. https://doi. org/10.1016/S1002-0160(19)60839-8

Guha A, Sengupta D, Kumar Rasineni G, Ramachandra Reddy A (2010) An integrated diagnostic approach to understand drought tolerance in mulberry (Morus indica L.). Flora Morphol Distrib Funct Ecol Plants 205:144-151. https://doi.org/10.1016/j.flora.2009.01.004

Guo Z, Ou W, Lu S, Zhong Q (2006) Differential response of antioxidative system to chilling and drought in four rice cultivars differing in sensitivity. Plant Physiol Biochem 44:828-836. https://doi.org/10.1016/j.plaphy.2006. 10.024

Gurley WB (2000) HSP101: a key component for the acquisition of thermotolerance in plants. Plant Cell 12:457-460. https://doi.org/10.1105/tpc.12.4 457

Haq NU, Raza S, Luthe DS, Heckathorn SA, Shakeel SN (2013) A dual role for the chloroplast small heat shock protein of Chenopodium album including protection from both heat and metal stress. Plant Mol Biol Rep 31:398-408. https://doi.org/10.1007/s11105-012-0516-5

Harb A, Awad D, Samarah N (2015) Gene expression and activity of antioxidant enzymes in barley (Hordeum vulgare L.) under controlled severe drought. J Plant Interact 10:109-116. https://doi.org/10.1080/17429145.2015. 1033023

Heath RL, Packer L (1968) Photoperoxidation in isolated chloroplasts. I. Kinetics and stoichiometry of fatty acid peroxidation. Arch Biochem Biophys 125:189-198. https://doi.org/10.1016/0003-9861(68)90654-1

Horváth G, Kissimon J, Faludi-Dániel Á (1972) Effect of light intensity on the formation of carotenoids in normal and mutant maize leaves. Phytochem 11:183-187. https://doi.org/10.1016/S0031-9422(00)89987-2

Hummel I, Pantin F, Sulpice R, Piques M, Rolland G, Dauzat M, Christophe A, Pervent M, Bouteille M, Stitt M, Gibon Y, Muller B (2010) Arabidopsis plants acclimate to water deficit at low cost through changes of carbon usage: an integrated perspective using growth, metabolite, enzyme, and gene expression analysis. Plant Physiol 154:357-372. https://doi.org/10. 1104/pp.110.157008

Jha Y, Subramanian RB (2018) From interaction to gene induction: an ecofriendly mechanism of PGPR-mediated stress management in the plant In: Egamberdieva D, Ahmad P (eds) Plant microbiome: stress response, microorganisms for sustainability. Springer, Singapore, pp 217-232 
Jochum MD, McWilliams KL, Borrego EJ, Kolomiets MV, Niu G, Pierson EA, Jo Y-K (2019) Bioprospecting plant growth-promoting rhizobacteria that mitigate drought stress in grasses. Front Microbiol 10:2106. https://doi. org/10.3389/fmicb.2019.02106

Kampinga HH, Craig EA (2010) The HSP70 chaperone machinery: J proteins as drivers of functional specificity. Nat Rev 11:579-592. https://doi.org/10. 1038/nrm2941

Kasim WA, Abo-kassem EM, Ragab GA, Sewelam NA (2014) Alleviation of lead stress toxicity in Vigna unguiculata by salicylic acid. Egypt J Exp Biol (Bot) 10(1):37-49

Kasim WA, Gaafar RM, Abou-Ali RM, Omar MN, Hewait HM (2016) Effect of biofilm forming plant growth promoting rhizobacteria on salinity tolerance in barley. Ann Agric Sci 61:217-227. https://doi.org/10.1016/j.aoas. 2016.07.003

Kasim WA, Osman ME, Omar MN, Abd El-Daim IA, Bejai S, Meijer J (2013) Control of drought stress in wheat using plant-growth-promoting bacteria. J Plant Growth Regul 32:122-130. https://doi.org/10.1007/ s00344-012-9283-7

Kato M, Shimizu S (1987) Chlorophyll metabolism in higher plants. VII. Chlorophyll degradation in senescing tobacco leaves: phenolic-dependent peroxidative degradation. Can J Bot 65:729-735. https://doi.org/10.1139/ b87-097

Kissimon J (1999) Analysis of the photosynthetic pigment composition. In: Proceedings of the international workshop and training course on microalgal. Biol Biotech Mosonmagyar Hungary, pp 13-26

Laemmli UK (1970) Cleavage of structural proteins during the assembly of the head of bacteriophage T4. Nature 227:680-685. https://doi.org/10.1038/ 227680a0

Loreto F, Velikova V (2001) Isoprene produced by leaves protects the photosynthetic apparatus against ozone damage, quenches ozone products, and reduces lipid peroxidation of cellular membranes. Plant Physiol 127:1781-1787. https://doi.org/10.1104/pp.010497

Mancosu N, Snyder RL, Kyriakakis G, Spano D (2015) Water scarcity and future challenges for food production. Water 7:975-992. https://doi.org/10. 3390/w7030975

Mittler R (2017) ROS are good. Trends Plant Sci 22:11-19. https://doi.org/10. 1016/j.tplants.2016.08.002

Naveed M, Mitter B, Reichenauer TG, Wieczorek K, Sessitsch A (2014) Increased drought stress resilience of maize through endophytic colonization by Burkholderia phytofirmans PsJN and Enterobacter sp. FD17. Environ Exp Bot 97:30-39. https://doi.org/10.1016/j.envexpbot.2013.09.014

Ngara R, Ndimba BK (2014) Understanding the complex nature of salinity and drought-stress response in cereals using proteomics technologies. Proteomics 14:611-621. https://doi.org/10.1002/pmic.201300351

Ngumbi E, Kloepper J (2016) Bacterial-mediated drought tolerance: current and future prospects. Appl Soil Ecol 105:109-125. https://doi.org/10. 1016/j.apsoil.2016.04.009

Nikolaeva MK, Maevskaya SN, Voronin PY (2017) Photosynthetic $\mathrm{CO}_{2} / \mathrm{H}_{2} \mathrm{O}$ gas exchange and dynamics of carbohydrates content in maize leaves under drought. Russ J Plant Physiol 64:536-542. https://doi.org/10.1134/S1021 443717030116

Omar AMN, Richard CL, Weinhard P, Balandreau J (1989) Using the spermosphere model technique to describe the dominant nitrogen-fixing microflora associated with wetland rice in two Egyptian soils. Biol Fert Soils 7:158-163. https://doi.org/10.1007/BF00292575

Omar MN, Osman ME, Kasim WA, Salama S (2017) Characterization of two drought-tolerant PGPB: Azospirillum brasilense NO40 and Stenotrophomonas maltophilia. JOESE 46(121):136

Omar MNA, Osman MEH, Kasim WA, Abd El-Daim IA (2009) Improvement of salt tolerance mechanisms of barley cultivated under salt stress using Azospirillum brasilense. In: Ashraf M, Ozturk M, Athar H (eds) Salinity and water stress. Tasks for vegetation sciences, vol 44. Springer, Dordrecht, pp 133-147

Oser BL (1979) Hawks physiological chemistry. McGraw-Hills, New York

Osman MEH, Kasim WA, Omar MN, Abd El-Daim IA, Bejai S, Meijer J (2014) Impact of bacterial priming on some stress tolerance mechanisms and growth of cold stressed wheat seedlings. Int J Plant Biol. 4:29-33. https:// doi.org/10.4081/pb.2013.e8

Osman MEH, Kasim WA, Omar MN, Salama S (2020) Using two plant growth promoting bacteria to sustainably reduce the drought-induced loss in
Triticum aestivum yield. Not Sci Biol 12(2):433-446. https://doi.org/10. $15835 /$ nsb12210580

Park CJ, Seo YS (2015) Heat shock proteins: a review of the molecular chaperones for plant immunity. Plant Pathol J 31(4):323-333. https://doi.org/10. 5423/PPJ.RW.08.2015.0150

Parsell PA, Lindquist S (1993) The function of heat-shock proteins in stress tolerance degradation and reactivation of damaged proteins. Annu Rev Genet 27:437-496. https://doi.org/10.1146/annurev.ge.27.120193.002253

Pirasteh-Anosheh H, Saed-Moucheshi A, Pakniyat H, Pessarakli M (2016) Stomatal responses to drought stress. In: Parvaiz A (ed) Water stress and crop plants: a sustainable approach. Wiley, Chichester, pp 24-40

Potters G, Pasternak TP, Guisez Y, Palme KJ, Jansen MAK (2007) Stress-induced morphogenic responses: growing out of trouble? Trends Plant Sci 12:98-105. https://doi.org/10.1016/j.tplants.2007.01.004

Reddy AR, Chaitanya KV, Vivekanandan M (2004) Drought-induced responses of photosynthesis and antioxidant metabolism in higher plants. J Plant Physiol 161:1189-1202. https://doi.org/10.1016/j.jplph.2004.01.013

Sairam RK, Deshmukh PS, Saxena DC (1998) Role of antioxidant systems in wheat genotypes tolerance to water tress. Biol Plant 41:387-394. https:// doi.org/10.1023/A:1001898310321

Sairam RK, Deshmukh PS, Shukla DS (1997) Tolerance of drought and temperature stress in relation to increased antioxidant enzyme activity in wheat. J Agron Crop Sci 178:171-178. https://doi.org/10.1111/j.1439-037X.1997. tb00486.x

Sairam RK, Srivastava GC, Agarwal S, Meena RC (2005) Differences in antioxidant activity in response to salinity stress in tolerant and susceptible wheat genotypes. Biol Plant 49:85-91. https://doi.org/10.1007/ s10535-005-5091-2

Salama S (2019) Enhancement of drought tolerance in Triticum aestivum using plant growth promoting rhizobacteria. Dissertation, University of Tanta, Egypt

Sarkar J, Chakraborty B, Chakraborty U (2018) Plant growth promoting rhizobacteria protect wheat plants against temperature stress through antioxidant signalling and reducing chloroplast and membrane injury. J Plant Growth Regul 37:1396-1412. https://doi.org/10.1007/s00344-018-9789-8

Selote DS, Khanna-Chopra R (2004) Drought-induced spikelet sterility is associated with an inefficient antioxidant defense in rice panicles. Physiol Plant 121:462-471. https://doi.org/10.1111/j.1399-3054.2004.00341.x

Seminario A, Song L, Zulet A, Nguyen HT, González EM, Larrainzar E (2017) Drought stress causes a reduction in the biosynthesis of ascorbic acid in soybean plants. Front Plant Sci 8:1042-1052. https://doi.org/10.3389/fpls. 2017.01042

Shabala S, Shabala L (2011) Ion transport and osmotic adjustment in plants and bacteria. Biomol Concepts 2:407-419. https://doi.org/10.1515/BMC. 2011.032

Sharma P, Jha AB, Dubey RS, Pessarakli M (2012) Reactive oxygen species, oxidative damage, and antioxidative defense mechanism in plants under stressful conditions. J Bot. https://doi.org/10.1155/2012/217037

Sharp RE, Hsiao TC, Silk WK (1990) Growth of the maize primary root at low water potentials. II. Role of growth and deposition of hexose and potassium in osmotic adjustment. Plant Physiol 93:1337-1346. https://doi.org/ 10.1104/pp.93.4.1337

Singh RP, Jha PN (2017) The PGPR Stenotrophomonas maltophilia SBP-9 augments resistance against biotic and abiotic stress in wheat plants. Front Microbiol 8:1945-1960. https://doi.org/10.3389/fmicb.2017.01945

Su X, Wei F, Huo Y, Xia Z (2017) Comparative physiological and molecular analyses of two contrasting flue-cured tobacco genotypes under progressive drought stress. Front Plant Sci 8:1-13. https://doi.org/10.3389/ fpls.2017.00827

Takahashi F, Kuromori T, Urano K, Yamaguchi-Shinozaki K, Shinozaki K (2020) Drought stress responses and resistance in plants: from cellular responses to long-distance intercellular communication. Front Plant Sci 11:556972. https://doi.org/10.3389/fpls.2020.556972

Timmusk S, Abd El-Daim IA, Copolovici L, Tanilas T, Kännaste A, Behers L, Nevo E, Seisenbaeva G, Stenström E, Niinemets Ü (2014) Drought-tolerance of wheat improved by rhizosphere bacteria from harsh environments: enhanced biomass production and reduced emissions of stress volatiles. PLOS ONE 9:1-13. https://doi.org/10.1371/journal.pone.0096086

Trivedi G, Patel P, Saraf M (2019) Synergistic effect of endophytic selenobacteria on biofortification and growth of Glycine max under drought stress. S Afr J Bot 134:27-35. https://doi.org/10.1016/j.sajb.2019.10.001 
Wei J, Li C, Li Y, Jiang G, Cheng G, Zheng Y (2013) Effects of external potassium (K) supply on drought tolerances of two contrasting winter wheat cultivars. PLoS ONE 8:1-11. https://doi.org/10.1371/journal.pone.0069737

Yang J, Kloepper JW, Ryu C (2009) Rhizosphere bacteria help plants tolerate abiotic stress. Trends Plant Sci 14:1-4. https://doi.org/10.1016/.jplants. 2008.10.004

Zhang K, Ezemaduka AN, Wang Z, Hu H, Shi X, Liu C, Lu X, Fu X, Chang Z, Yin CC (2015) A novel mechanism for small heat shock proteins to function as molecular chaperones. Sci Rep 5:1-8. https://doi.org/10.1038/srep0 8811

\section{Publisher's Note}

Springer Nature remains neutral with regard to jurisdictional claims in published maps and institutional affiliations.

\section{Submit your manuscript to a SpringerOpen ${ }^{\odot}$ journal and benefit from:}

- Convenient online submission

- Rigorous peer review

- Open access: articles freely available online

- High visibility within the field

- Retaining the copyright to your article

Submit your next manuscript at $\boldsymbol{\nabla}$ springeropen.com 